\title{
Analysis on the current study about personalized learning system within domestic research - Based on the content analysis of the research literature from 2002 to 2015
}

\author{
Jiachun $\mathrm{Li}^{1, \mathrm{a}}$, Shuguang Chen ${ }^{2, \mathrm{~b}}$ \\ ${ }^{1,2}$ School of Hunan University, Changsha 410000, China; \\ a1412891540@qq.com, b904428285@qq.com
}

Keywords: personalized learning; learning system; content analysis

\begin{abstract}
The article uses content analysis method, using CNKI database as a search tool to retrieve the relevant papers published during the period of 2002-2015.By comparing, analyzing and integrating the research history, research types, research topics, research content and so on ,we think the further development of personalized learning system can not be separated from the support of mobile technology and the integration of subject knowledge, in order to provide reference for the study of personalized learning system.
\end{abstract}

\section{Introduction}

Cloud computing, Internet of things, big data, mobile computing, 3D printing and other new technology development, has promoted the change of learning methods. Smart education is the inevitable trend of educational reform. Smart learning is the cornerstone of smart education ${ }^{[1]}$, also the new development of contemporary education information. Personalized learning system as a platform to carry on the idea of personalized education is attracting the attention of scholars. Now, what is the research status of personalized learning system? What progress has been made? What will be the future development trend? Therefore, it is necessary to analyze the domestic research of the personalized learning system in recent years.

\section{Research method and design}

Content analysis is a scientific method which can find the essence through the phenomena based on the analysis of the content, aiming at the development trend and essential facts of the study object. In this paper, the research literature mainly comes from CNKI. Choose "personalized learning system" or "personalized learning platform" as keywords. There are 202 literatures from the beginning of 2002, only three related literatures in 2016, retrieval time is May 1, 2016. By reading the paper topics, abstract and through the paper content, we screen the retrieved papers. After excluding articles only introducing learning system, news and inconsistent with the theme of the reference, besides considering the download and citation frequency of these documents, we deleted 47 articles, left 152.

Traditional category classification method is: category code in advance, reliability analysis, classification and literature classification. While this paper is based on the Grounded Theory: first read the literature, and then code and classificate the literature. The core meaning is encoding the factual experience data, namely "data decomposition, conceptualization, and recombine the concept in a new way, then enhance it as a guiding significance theory" ${ }^{[2]}$. Thus, we get the following content analysis category table after decomposition, comparison, integration, conceptualization and categorization of correlated variables in the sample. 
Table 1 Detailed category of the domestic personalized learning system research

\begin{tabular}{|l|l|}
\hline Variables & values \\
\hline Research process & \multicolumn{1}{|c|}{} \\
\hline Research type & $\begin{array}{l}\text { Theoretical research, Explanatory research } \\
\text { development research, others }\end{array}$ \\
\hline Research themes & High frequency keywords \\
\hline Research content & Learning style, key technology, core theory \\
\hline
\end{tabular}

\section{Research results and analysis}

\subsection{Research process}

In this paper, the research literature is from the beginning of 2002. In view of the characteristics of academic papers and dissertations, it can be considered that the academic paper represents the breadth of the study of personalized learning system, while the dissertation on behalf of the depth ${ }^{[3]}$. From Fig.1, we can find that there is not much change within the published literature by 2004, namely it did not cause extensive concern of education researchers. Until 2005, related literature quantity showed a rapid growth, then stabilized , presents ascendant trend since 2013.

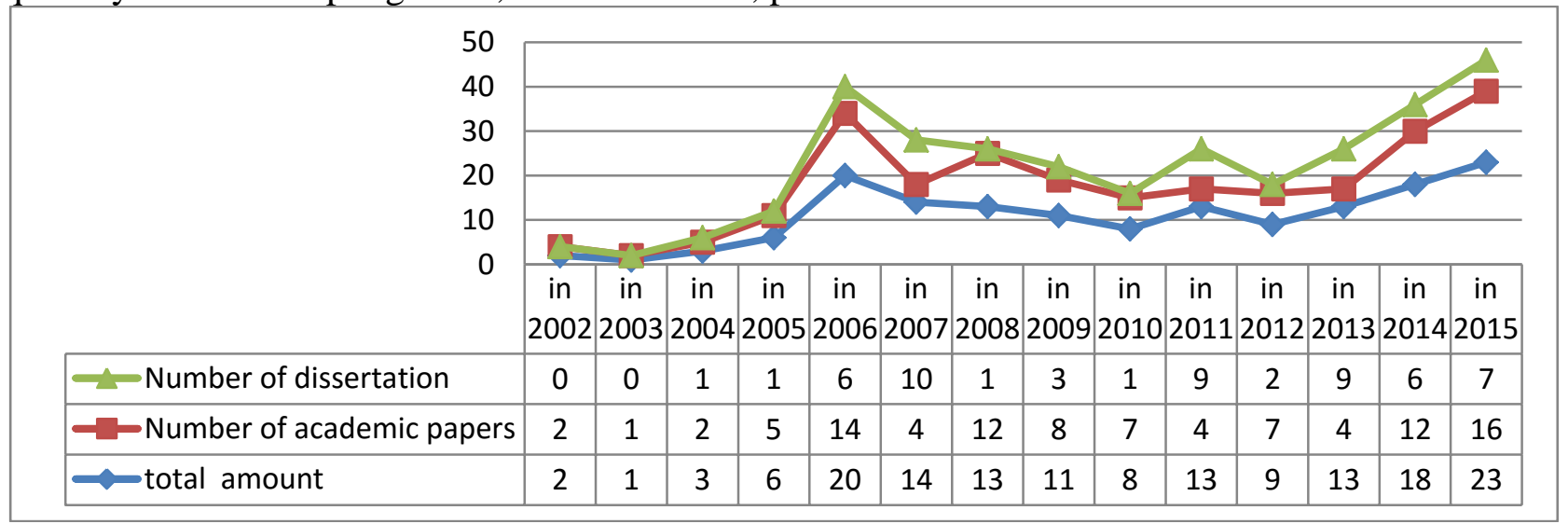

\subsection{Research types}

Fig. 1 Annual distribution of realated literature about personalized learning system

Research type is an abstract generalization of the general research methods of scientific research activities, which can reflect the research methods and ideas of the researchers ${ }^{[4]}$. In view of the existing paper category design, this article designs the research type for four dimensions: theoretical research, explanatory research, development research and others. Among them, the theoretical research refers to the description with the theory of logical analysis and deduction, eventually form a theoretical research results; Explanatory research and theoretical research's difference lies in: explanatory research will formate the strategy or specific solutions to solve the problem after the theory description; Other researchs means cannot clear judge the types of articles.

From Table 2, we can see that research types focus on theoretical research and interpretation, especially before 2010, development study is less, the scholars mainly focus on the basic theory research and consideration of all kinds of phenomena and analysis, only gradually towards development research in recent years. Theoretical research mainly discusses the design of personalized learning system model, the implementation of the strategy and all kinds of technology in the application of the personalized learning system. Explanatory research is much , which reflects the new phenomenon of interpretation and thinking is getting more and more with the rise of technologies, especially application of cloud computing, data mining and all kinds of algorithms. 
Table 2 distribution of research types

\begin{tabular}{|c|c|c|c|c|c|c|}
\hline \multicolumn{7}{|c|}{ Research types } \\
\hline & & Theoretical research & Explanatory research & Development research & others & Total \\
\hline \multirow{14}{*}{$\begin{array}{l}\text { paper } \\
\text { publish } \\
\text { time }\end{array}$} & 2002 & 2 & 0 & 0 & 0 & 2 \\
\hline & 2003 & 0 & 1 & 0 & 0 & 1 \\
\hline & 2004 & 0 & 1 & 1 & 1 & 3 \\
\hline & 2005 & 3 & 1 & 2 & 0 & 6 \\
\hline & 2006 & 8 & 7 & 4 & 0 & 19 \\
\hline & 2007 & 2 & 7 & 3 & 2 & 14 \\
\hline & 2008 & 4 & 6 & 3 & 0 & 13 \\
\hline & 2009 & 2 & 7 & 2 & 0 & 11 \\
\hline & 2010 & 2 & 6 & 0 & 0 & 8 \\
\hline & 2011 & 3 & 7 & 3 & 0 & 13 \\
\hline & 2012 & 1 & 3 & 3 & 2 & 9 \\
\hline & 2013 & 3 & 4 & 5 & 1 & 13 \\
\hline & 2014 & 4 & 9 & 5 & 0 & 18 \\
\hline & 2015 & 7 & 10 & 6 & 0 & 23 \\
\hline \multicolumn{2}{|l|}{ Total } & 41 & 69 & 37 & 6 & 153 \\
\hline
\end{tabular}

\subsection{Research themes}

There are 387 keywords after import 152 papers into Bicomb software to analyze the high frequency keywords. 76 keywords appear more than 2 times, the cumulative percentage of $53.4431 \%$, while 35 keywords appear more than 3 times, the cumulative percentage of $41.1677 \%$. Select frequency keywords which appear more than 2 times, and use Bicomb software to generate the word matrix. In order to further explore the research topic of personalized learning system, we can import the key words in the matrix into SPSS to cluster the key words, and make the close relationship ones into a class to represent a certain field. The formation of the theme clustering diagram is shown in Fig.2.

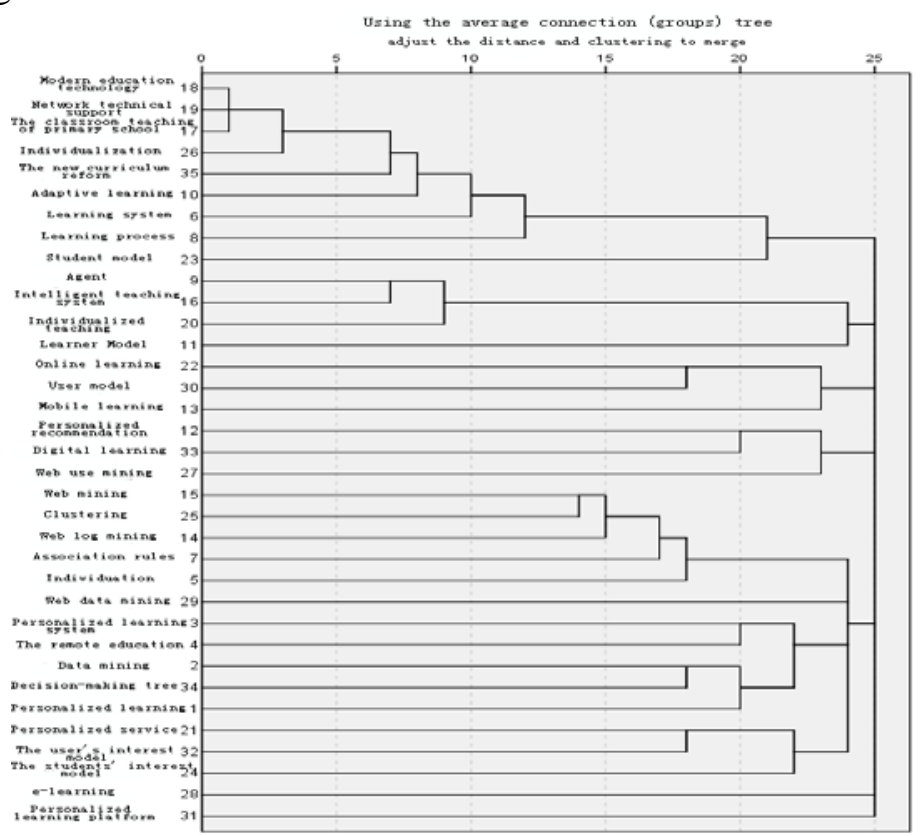

Fig. 2 Thematic clustering graph

According to the result of clustering analysis, the personalized learning system can be divided into the following three classes: The application of personalized learning system in teaching, The implementation support of personalized learning system, Model construction of personalized 
learning system.

\subsection{Research content}

Personalized learning system is inseparable from the learning style of research and Felder Silverman learning style models are very famous. Through the detailed reading for 152 paper, we found that the construction of personalized learning platform, is the key to match the individual way. Personalized matching methods can be divided into based on rules, based on the algorithm and the mixed. The core of personalized learning theory mainly for are multiple intelligence theory and metacognitive theory and humanism theory, etc. This paper argues that the new constructivism learning theory provides a new perspective for personalized learning. The theory was promoted by Zhuli Wang in Sun Yat-sen University. The learning methods New constructivism learning theory advocated have the same effect with personalized learning.

\section{Summary}

Through the analysis of the above research on personalized learning system, we can see, in the domestic research it has had some effect, but the further research of space is still large, mainly in teaching research, applied research, technology, etc. According to the present situation of personalized learning system, this paper puts forward the following Suggestions:

\subsection{Reflection about mobile technology applied in the personalized learning system}

At present, mobile phones and other mobile devices have been widely exist, and can support personalized learning, but in the sample document about mobile personalized learning system research ,there is not too much, also is not thorough, it mainly discuss the education theory, learning theory and its application in mobile learning. Research about handheld terminal software development in mobile learning is less.

\subsection{Effective integration of personalized learning system and discipline}

The construction of personalized learning system can not be separated from the specific subject content, or it maybe only stay at the technical level, and no substantive application research. In order to truly achieve personalized learning and the student as the main body, you must consider the content to realize "personalized," then provide their own level of personalized service for students with different levels of knowledge, learning style.

\section{References}

[1] Zhiting Zhu, Hebin. Smart education: The new state of education informatization[J].e-Education Research. 2012(12).

[2]Zhuhong. The Research on Open Online Courses in China-Content Analysis of High Impact Educational Journals[A].Proceedings of the twelfth academic annual conference of the China Institute of Higher Education[C].2014.

[3] Jianshe Liu,Liqing, JinmeiLiu. Summary of current research on Mobile Learning[J]. e-Education Research,2007,(7):21-25.

[4] Shigai Li. Content analysis of excellent master's thesis in educational technology in recent five years[J]. e-Education Research,2008,(1). 